\title{
La imagen pública de la química y su relación con la generación de actitudes hacia la química y su aprendizaje
}

Artículo recibido: 30-05-2009 | Aprobado: 12 -11-2009

The Public Image of Chemistry and its Relationship with the

Generation of Attitudes towards this Science and its Learning

\section{William Manuel Mora Penagos*}

Diana Lineth Parga Lozano*

Resumen: El presente ensayo muestra cómo la imagen popular y escolar de la química se caracteriza por ser negativa, lo que viene incidiendo en la generación de actitudes negativas hacia esta ciencia y su aprendizaje. Las inadecuadas formas de comunicación del conocimiento de la química que se muestran en el cine, la TV y las revistas de ciencia popular, la visión irreconciliable entre ciencia y religión, y la poca claridad de las formas de producción del conocimiento químico mostradas en las aulas de clase, aparecen como las principales causas de esta situación. Superar esta imagen implica reconciliar la visión científica con la visión social de la química, por lo que el conocimiento en epistemología e historia de la química y la línea de investigación conocida como Public Understanding of Science desde el enfoque Ciencia/Tecnología/ Sociedad y Ambiente (CTS-A), son fundamentales para una didáctica de la química orientada hacia la alfabetización en química y a la formación docentes en torno al diseño curricular y la enseñanza de contenidos articulados a la generación de actitudes hacia el impacto social y ambiental de la química.

Palabras clave: imagen pública de la química, actitudes hacia la química, historia y epistemología de la química, enseñanza de la química, ciencia / tecnología / sociedad / ambiente, alfabetización química.

\begin{abstract}
This essay shows how the academic and popular image of Chemistry is negatively distinguished, generating negative attitudes towards this science and its learning. The inappropriate communication ways of Chemistry knowledge shown by films, TV and popular science magazines, the division and conflict between science and religion, and the lack of clarity regarding the ways Chemistry knowledge production is revealed in classrooms, are the main causes of this situation. Overcoming this image means to reconcile the scientific view with the social vision of Chemistry, so that the knowledge of epistemology, the history of Chemistry and the line of research known as the Public Understanding of Science, taken from the Science/Technology/ Society and Environment -STS/E- approach, become essential for Chemistry teaching, which needs to be oriented towards a Chemistry literacy and teachers training based on the curriculum design and contents teaching articulated to attitudinal generation towards social and environmental impact of Chemistry.
\end{abstract}

Keywords: Public Image of Chemistry, Attitudes towards Chemistry, Chemistry History and Epistemology, Chemistry Teaching, Science/Technology/Society/ Environment, Chemistry Literacy.

* Profesor de carrera. Universidad Distrital Francisco José de Caldas. Grupo de Investigación DIDAQUIM. wmora@udistriatal.edu.co

* Profesora del Departamento de Química de la Universidad Pedagógica Nacional. Grupo de Investigación ALTERNACIENCIAS.dparga@pedagogica.edu.co 


\section{Introducción}

Hoy, nadie pone en duda el papel que la química como ciencia ha tenido para la sociedad, en la comprensión del mundo, en la evolución de las ideas, en la modificación del ambiente, y en el progreso material de la humanidad, por lo que sería lógico pensar que este gran impacto de la química debería tener como consecuencia el que despertara un gran interés hacia ella y su estudio. Sin embargo y como lo presentan Schummer, Bensaude-Vincent, y Van Tiggelen (2006), de todas las disciplinas científicas la química parece ser la que más ha calado en la imagen negativa del público, siendo popularmente la química asociada con venenos, peligros, guerra química, contaminación ambiental, pasando por aspectos pseudo-científicos de la alquimia, hasta la brujería y la esquizofrenias de científicos enojados. Es decir, que la imagen popular que se tiene de la química destaca en gran medida por ser negativa, al ser entendida como una actividad misteriosa, extraña, mística, sombría y peligrosa.

Hay algo que todos apreciamos y es que la química al igual que otras ciencias, está saturando el tipo de sociedad en que ahora nosotros vivimos, presentándose como ubicua, como diría Zeeman (2003), a veces se encuentra como una tecnología útil (como los plásticos biodegradables); a veces es encontrada como una medicina salvavidas (como la penicilina, o la vacuna contra el SIDA); a veces es encontrada como un augurio de sentencia (como las predicciones de desastre climático por el aumento de los gases de efecto invernadero; o la mejora de la especie humana mediante técnicas de clonación); a veces, como un peligro latente (del enriquecimiento de material nuclear con la sospecha de no tener fines energéticos para la sociedad, sino como un instrumento aterrador del poder político para la construcción de armas); a veces, como una encantación misteriosa (de los elixires que revitalizan y devuelven la juventud). Todo esto es un reflejo de la imagen ambigua de amor y odio que se evidencia, por un lado, en la fe hacia el bienestar de la moderna tecno ciencia, pero por otro lado, también genera miedos ante el progreso, pensándose así que "algunas cosas deben permanecer ocultas o lejos del alcance humano".

Junto a la ciencia de afectos contrarios, nos encontramos también con la ciencia de corte heroica, aventurera, fantástica, casi cinematográfica complementada con el extenso tratamiento que reciben en periódicos y revistas al tiempo que inspiran películas, relatos y series de ficción destinadas no a informar, sino a entretener a un público sin conocimientos científicos, en su mayoría jóvenes o personas de mediana edad deseosas de satisfacer su curiosidad o adquirir unos conocimientos que no pudieron conseguir en su momento (Llopis, 2003). Esta situación ha generado una difícil relación entre quienes trabajan en el medio académico de la química y los periodistas, con sus lenguajes aparentemente irreconciliables (el rigor y la incomprensibilidad por una parte, y el sensacionalismo y la simplificación exagerada, por otro).

La imagen fantástica de la ciencia, de los científicos y sus laboratorios mostrada particularmente en el cine de ficción, y que han sido presentados por guionistas y escritores, algunos poco escrupulosos, en trabajos como Fausto, Frankenstein, Moreu o Jekyll, y en los enemigos de Batman, Superman y Spiderman, ofrecen imágenes de laboratorios científicos, como lugares grotescos y sombríos ubicados en lugares ocultos en los sótanos de los castillos o de casas antiguas asociados con fuerzas sobrenaturales, que poco, o nada, tienen que ver con los laboratorios reales; así mismo se presentan los científicos como genios locos, despistados, 
La imagen pública de la química y su relación con la generación de actitudes hacia la química y su aprendizaje William Manuel Mora Penagos | Diana Lineth Parga Lozano

torpes, olvidadizos que trabajan en solitario, con actitud quimérica que están alejados de las problemáticas reales de la sociedad, lo que puede llegar a generar actitudes hostiles y anticientíficas. Resulta curioso constar que el personaje del científico loco aparece en más filmes de terror que otros personajes característicos, como zombis, hombreslobo o momias juntos (Tudor, 1989).

Un estudio sobre la evolución de las representaciones del científico en la literatura y cinematografía occidentales, realizado por Haynes (1995) y citado por Moreno (2001), nos muestra una imagen de los científicos en seis grupos: El alquimista medieval: científico maníaco y obsesivo, que persigue un objetivo intelectual que entraña aspectos diabólicos en relación con quimeras como la transmutación de los metales innobles en oro, y que actualmente se reencarna en el bioquímico siniestro que produce nuevas especies mediante ingeniería genética; el sabio despistado: que no pone los pies en el suelo, ignorante de sus responsabilidades sociales, más cómico que siniestro; el científico romántico: que reniega de cualquier relación y sentimientos humanos en pro de la ciencia, figura ambivalente: considerado inhumano por su deficiencia emocional, pero objeto de admiración por su dedicación a la ciencia y de lástima por el precio que paga para conseguir sus objetivos; el aventurero heroico: explorador de nuevos territorios físicos o intelectuales, carismático, excéntrico e irascible, típico de periodos de optimismo y confianza en la ciencia; el científico desvalido: que ha perdido el control sobre sus creaciones o descubrimientos, irresponsable, causante de problemas (medioambientales, etc.); y el científico idealista: que es bueno por naturaleza, antepone valores éticos y humanos al progreso tecnológico desbocado, aunque, a veces, sus ideales le llevan a actuar contra sus semejantes.
En muchos filmes sobre fenómenos paranormales, siempre aparece algún científico o mente racional que duda de estos fenómenos y pone en peligro a los protagonistas que acaban rechazando este punto de vista, allí el científico y la ciencia resultan del todo ineficaces y los pseudocientíficos son quienes acaban con las amenazas, sean sobrenaturales o de otro tipo por lo que la ciencia parece no sólo incapaz de resolver los problemas sino que, a menudo, se convierte en un obstáculo (Moreno, 2001), de esta manera, y como lo dijera Carl Sagan (2002): la pseudociencia y la superstición colman las necesidades poderosas que la ciencia suele dejar insatisfechas, dejado la puerta abierta y generando una tendencia global a creer, por ejemplo en la astrología y la adivinación como parte de las soluciones a los grandes problemas actuales de la humanidad, inclusive entre líderes gubernamentales. Arquetipos que han permanecido prácticamente invariables y que muy poco, o nada, tienen que ver ya con la actividad científica real y que si han dejado el camino abierto a la irracionalidad, retornando a una situación de hostilidad a la actividad científica propias de la edad media.

Otro campo en el que se han generado múltiples tensiones en la imagen pública de la química ha sido en el plano de las relaciones entre ciencia y religión, y en donde la creencia popular es que ellas son incompatibles y que los científicos, por lo general, son no creyentes en una entidad superior debido, entre otras, al impacto histórico del lado rígido, doctrinario, conservador y fundamentalista de la religión. Artigas (1995) muestra como producto de entrevistas a 100 personas entre ellas trabajadores de las ciencias de profesión, profesores mayoritariamente catedráticos o licenciados en economía, ingenieros industriales, o doctores o licenciados en ciencias, encontrando que los entrevistados que son científicos 
(o han estudiado ciencias) no ven ninguna oposición entre ciencia y religión (no dogmatizante), y que, por el contrario, quienes piensan que esa oposición existe son personas que, aunque sean cultas, no se han dedicado a la ciencia, es decir que, entre personas con un impacto social importante, las que tienen mayor relación con el mundo de la ciencia suelen ser las que no ven dificultades para compaginar la ciencia y la religión.

Fernández - Rañada (2008), en su libro "Los Científicos y Dios", sostiene que las relaciones entre ciencia y religión se han entendido a menudo de modo simplista, sin tener en cuenta que han sido muy variadas y de gran complejidad y riqueza; y que la ciencia y muchas formas de religión son plenamente compatibles. Este autor nos dice que ante las posiciones del mundo intelectual que consideran que la ciencia se opone necesariamente a la fe en cualquier forma de Dios (donde todos los científicos son necesariamente ateos), o su antípoda, que por el contario, sostiene que la ciencia puede acercarnos a Dios (pues le permite comprender mejor su obra), nos muestra una tercera posición intermedia, defendida por ejemplo por el químico y biólogo francés Louis Pasteur (1822-1895) quien sostenía que "un poco de ciencia aleja de Dios, mucha ciencia acerca de nuevo a Dios". En consonancia la relación entre ciencia y religión puede ser en general de tres tipos: primero, de conflicto inevitable, considerando la ciencia y la religión como estructuras antagónicas e incompatibles, enfrentadas intensa y necesariamente por sus métodos, fines y estilos (Appleyard, 2004; Dampier, 1986); segundo, de independencia aceptándose tener ámbitos de actuación completamente diferentes, de manera que todas sus disputas se deben a malentendidos; y tercero, de cooperación (Jay Gould, 1999), donde ciencia y religión podrían ayudarse mutuamente en casos de situaciones alarmantes como es el caso de los pro- blemas ambientales que amenazan incluso la continuidad de la especie humana en el planeta Tierra. Así el físico y astrónomo Carl Sagan (1934-1996) considerado como el portavoz del cientificismo y muchas veces opuesto a la interpretación religiosa del mundo, ante la crisis ambiental global llegó a convencerse de la necesidad de cooperación entre ciencia y religión redactando un llamamiento titulado "Preservar y Proteger la Tierra" firmado por treinta y dos científicos destacados y cientos de dirigentes religiosos de ochenta y tres países, para dar soluciones a lo que en el lenguaje religioso se podría llamar crímenes contra la Creación.

Este escenario de ambivalencia, de amor / odio hacia la química y sus científicos se sitúa por tanto en el terreno de la abundancia de medios de comunicación y su enorme capacidad de información, por un lado, y por otro, en la escasa formación educativa y científica de unos ciudadanos que viven esclavizados por una industria hipertecnológica de bienes de consumo y una imperante mentalidad mercadotécnica (Tena, 2003). Las voces de la mayoría de los medios de comunicación, la industria, los partidos políticos, los gobiernos, cantan la misma canción de que la tecnociencia hace todas las cosas posibles generando falsas ideas que hacen de las ciencias y de la química una "piedra filosofal" que da solución a todos los problemas humanos. Políticos y economistas de los países desarrollados dicen continuamente que el papel fundamental de la ciencia es guiar e informar la vida práctica, particularmente por sus aplicaciones, que pueden explotarse en beneficio de varias causas como la "riqueza de la creación del conocimiento", "la competitividad internacional", "la seguridad nacional", "la salud pública", o "el bienestar social". Sin embargo, creemos que aunque la ciencia es un bien de la humanidad sin la cual difícilmente la cultura moderna hubiera sido viable, y posi- 
La imagen pública de la química y su relación con la generación de actitudes hacia la química y su aprendizaje William Manuel Mora Penagos | Diana Lineth Parga Lozano

blemente estaríamos en el oscurantismo y la tiranía, actualmente muchos académicos advierten del peligro de que sea considerada como la solución a todos los problemas humanos e invitan a reconceptualizar la ciencia en la dirección de permitir una unión entre racionalidad y emoción para así hacerla más abierta, democrática, pluralista, crítica, fiable, e independiente; estos elementos son suficientes para contribuir a mejorar su imagen en el plano educativo.

Ante la situación mostrada, los químicos se han estado quejando por su bajo prestigio y la carencia del reconocimiento público de sus logros, por lo que han intentando, como estrategia, sustraer el término química del conjunto de la disciplina para adoptar etiquetas tales como "ciencia de los materiales", "ciencia molecular", "ciencia central", o "ciencia de la nanotecnología", y lanzar lemas tales como "química verde" y "química sustentable", pero asombrosamente la comunidad de profesionales de la química difícilmente han enfrentado esta problemática desarrollando verdaderos programas de investigación para entender cómo esa imagen poco positiva de la química ha estado dificultando y/o contribuyendo a facilitar la formación de una imagen adecuada y generadora de actitudes hacia la química y su aprendizaje en sus distintos contextos histórico culturales, populares y académicos. Creemos que la falta de atención, de manera suficiente, al campo socio humanístico de la química en particular de su filosofía, historia, sociología, psicología, y didáctica, es una seria deficiencia que ha contribuido a la generación y persistencia de estereotipos negativos que afectan no sólo la motivación para estudiar y formarse en las distintas áreas de la química sino también en la formación y ejercicio docente.

Es evidente que el público en general no comprende la naturaleza de la empresa científica de la química, e infravalora y tergiversa continuamente lo que supone "ser científico" presentándose una situación de "analfabetismo científico de la química". Estas preocupaciones han conducido recientemente, a la creación de una de las líneas de investigación internacional de más desarrollo en los últimos años tanto en Sociología, Epistemología, y Enseñanza de la química, como es el campo conocido como: "Public Understanding of Science" (Comprensión pública de la ciencia), contribuyendo a que la imagen pública la química salga del guardapolvo y de los terraplenes de la ciencia para contribuir a entender la relación entre la ciencia y la sociedad, como bien es planteado por Joachim Schummer y Bernadette Bensaude-Vincent, en la editorial del Vol. 12, No.1 de 2006 de la revista HYLE (International Journal for Philosophy of Chemistry).

Esta nueva área de investigación ha contribuido a la reflexión sobre la naturaleza de la química - en torno a sus orígenes, formas de proceder, objetos de conocimiento, realizaciones, luchas entre científicos y comunidades, las implicaciones sociales y su posible futuro que vienen a contribuir al cambio de su imagen- $y$ aportan a clarificar polémicas relacionadas a su parentesco con otras formas de conocimiento (o dimensiones de la cultura) que fueron condenadas históricamente, como la brujería o la magia, durante la edad media y moderna, sino también, y como otro ejemplo, a su dependencia de la actual física atómica, como de su autonomía histórica como disciplina científica que tiene desde sus orígenes hace más de doscientos años, a partir de la rivalidad de las teorías del flogisto (Propuesta por Stalh y sus seguidores) con la teoría del oxígeno de Lavoisier a finales del siglo XVIII, posteriormente en el siglo XIX (Teoría atómico molecular vs. equivalentismo), y en química orgánica (unitarismo vs. dualismo), (teoría 
de los tipos vs. teoría estructural), y finalmente en el siglo XIX (las teorías precuánticas vs. Las teorías cuánticas) (Mora y Parga, 2005; Mora y Parga, 2008).

\section{Importancia de la historia y la epistemología de las ciencias en la didáctica de la química}

En el plano de la educación formal, contribuir a una educación científica que desmitifique la química y la haga más accesible, puede conducirnos a revisar histórica, epistemológica y didácticamente la naturaleza de la química desde sus orígenes, desarrollos y compromisos, analizando sus métodos, teorías, conceptos y disputas de sus protagonistas, con el fin de (Llorens, 1991):

- Evitar dar una visión simplista de la evolución de las ideas científicas de la química que suelen identificar la alquimia con oscurantismo donde el alquimista se presenta como un espíritu trastornado al servicio de una quimera propia de un corazón codicioso que quiere enriquecerse fabricando oro. Tal vez ya no son los bienes terrestres los que persiguen esos soñadores sino la superación y perfeccionamiento del alma, donde los éxitos o fracasos de los experimentos alquímicos depende más de la pureza moral del experimentador, por tanto se trata de una iniciación no tanto académica como si moral. O que las ideas atomísticas parecen viajar a través del "túnel del tiempo" desde Demócrito hasta Dalton.

- Evitar presentar las teorías como verdaderas o falsas, juzgándolas a la luz del conocimiento actual, sin poner de manifiesto que en su momento fueron esquemas conceptuales útiles para interpretar las experiencias conocidas y abrir nuevos caminos. Es lo que ocurre con la doctrina de los elementos o la teoría del flogisto. Y es también lo que ocurre con las ideas alternativas de los alumnos que, o bien son ignoradas, o bien consideradas como falsas, debiendo ser sustituidas por los conocimientos, naturalmente más científicos, que con la autoridad nosotros los profesores les impartimos.

- Evitar mostrar una visión del progreso científico basada en las ocurrencias de personajes especialmente geniales, que aparentemente son capaces de crear de la nada una nueva teoría y que vivieron en el limbo, ajenos al tiempo y al espacio, trabajando día y noche en su laboratorio. El mismo lenguaje que utilizamos es muy revelador en expresiones como "Padre de la química". Quizás deberíamos esforzarnos más en presentar el trabajo científico como la labor de una comunidad, con sus inherentes conflictos e intereses y sometida a todo tipo de influencias sociales, culturales y económicas.

- Evitar la visión inductivista - empirista que considera todo planteamiento teórico consecuencia de la pura observación de unos determinados hechos experimentales. Por ejemplo, los datos empíricos en los que se basó Lavoisier ya eran previamente conocidos. Sin embargo, hubo que interpretarlos desde un nuevo esquema conceptual para que fueran fructíferos. La aceptación de la teoría del flogisto, existiendo conocimientos experimentales que podrían haber fundamentado ideas, desde nuestro punto de vista, más adecuadas, muestra la importancia que tiene la coherencia de un esquema conceptual a la hora de resistir a ser remplazado por otro. No basta una evidencia experimental que justifique su rechazo, pues puede ser, frecuentemente 
La imagen pública de la química y su relación con la generación de actitudes hacia la química y su aprendizaje William Manuel Mora Penagos | Diana Lineth Parga Lozano

interpretada plausiblemente en términos de la vieja teoría.

En general los estudios históricos, muchos de ellos, con fines didácticos en química han concluido que la historia es importante en varios sentidos (Navarro, 1983; Gagliardi, y Giordán, 1986; Llorens, 1991):

- Mostrar que los conocimientos científicos actuales no son "verdades eternas" sino construcciones en un contexto social definido, entendiendo que en cada momento los científicos eran coherentes, es decir que "no pensaban en términos actuales", sino que utilizaban las herramientas lógicas de su medio y de la época.

- Permite definir cuáles fueron los conceptos estructurantes presentes en los momentos de profunda transformación de una ciencia.

- Mostrar que los conocimientos científicos no son el resultado de una simple acumulación de observaciones ni de la utilización de nuevos aparatos complicados, sino de la utilización de nuevos métodos de análisis y de nuevas teorías.

- Puede mostrar en detalle algunos momentos de transformación profunda de una ciencia e indicar cuáles fueron las relaciones sociales, económicas y políticas que entraron en juego, cuáles fueron las resistencias a la transformación y que sectores intentaron impedir los cambios.

- Dar herramientas conceptuales para que los alumnos comprendan la situación actual de las ciencias, su ideología dominante y los sectores que la controlan y que se benefician con los resultados de la actividad científica.
- Proponer estrategias de enseñanza de los principales conceptos, teniendo en cuenta aquellas dificultades que los alumnos tienen para acceder a los nuevos significados.

Jean Pierre Astolfi (2001) considera que "la epistemología constituye hoy una de las bases más sólidas de la didáctica de las ciencias y en general, de toda reflexión pedagógica ocupada por la enseñanza y apropiación de los saberes científicos... en la medida en que permite dilucidar las condiciones de la producción del saber," y de esta manera permite tener una visión crítica, renovada y enriquecida de las ciencias, susceptibles de influenciar no sólo las prácticas educativas en docentes y estudiantes, sino la imagen pública en general. Por otro lado, para Astolfi (2001) "Ia historia de las ciencias constituye, sin duda, la rama de la epistemología que se invoca con mayor frecuencia al servicio de la pedagogía y la didáctica, desde la célebre obra La formación del espíritu científico, de Gastón Bachelard".

Epistemólogos (científicos y filósofos que se han dedicado a la reflexión crítica sobre la naturaleza del conocimiento científico, particularmente sobre el cambio de las teorías y métodos como también de los elementos de racionalidad usados en la producción de sus realizaciones) con conciencia histórica como Bachelard, Koyré, Kuhn, Feyerabend, entre muchos, han trabajado en la reconstrucción de hechos y acontecimientos, analizando la evolución de conceptos y la caracterización de las formas de pensamiento inherentes al desarrollo científico, que han sido muy valiosas para el interesado en las ciencias.

Como ejemplo de una reconstrucción histórico epistemológica de la química veamos algunos de los aportes que a comienzos del siglo XX el químico y epistemólogo francés Gastón Bachelard (1978) propuso. Bachelard describe tres etapas del desarrollo del pensamiento científico: el estado precien- 
tífico, propio de la antigüedad clásica y los tiempos del renacimiento (realizaciones hasta incluso el siglo XVIII), el estado científico, periodo donde nace la química como disciplina racional (desde finales del siglo XVIII y comienzos del XX), y el estado del nuevo espíritu científico que se inicia con los trabajos sobre la relatividad y la mecánica cuántica, en la que el pensamiento humano realiza elaboraciones abstractas substraídas a la intuición del espacio real y desligadas de la experiencia inmediata. En el camino de transformación de una etapa a otra se presentan tres momentos de producción del conocimiento, que no necesariamente son secuenciales entre si, primero: el saber se conquista en contra de obstáculos; segundo se construye el conocimiento y a continuación se comprueba.

En este paso del conocimiento cotidiano al conocimiento científico, (entendido como desarrollo del "espíritu científico"), el pensamiento debe proceder en contra de los conocimientos anteriores, reconstruyendo y destruyendo aquellos mal hechos, es decir, superando una serie de "obstáculos de tipo epistemológico" acumulados por la vida cotidiana que entorpecen los nuevos aprendizajes (entre estos obstáculos se destacan: la experiencia básica, el conocimiento no interrogado de la opinión, las ideas valorizadas indebidamente, las analogías inapropiadas que impiden la abstracción, el substancialismo o tendencia a entender las propiedades como por ejemplo el color, olor, sabor como si estuvieran formados por materia, y el antropocentrismo o tendencia a suponer que todo en la naturaleza está al servicio humano, entre otras).

Si tomamos el obstáculo verbal, Bachelard nos plantea como ejemplo el concepto de esponja como extensión abusiva de las imágenes familiares del pensamiento precientífico y cotidiano que intenta explicar el comportamiento de los gases, citando un artículo de Réaumur que apareció en las Mémories de l'Académie des Sciencies en 1731: "Una idea bastante vulgar es la de considerar el aire como algodón, como lana, como esponja, y mucho más esponjosa que todos los demás cuerpos o reunión de cuerpos con los que se puede comparar. Esta idea es apropiada para explicar por qué el aire se deja comprimir notablemente mediante pesos, por qué puede ser también enrarecido considerablemente, y aparecer bajo un volumen que sobrepasa en mucho aquél en el cual lo habíamos visto anteriormente". Esta imagen intuitiva y evidente a la razón, y en la que el pensamiento concreto acumulado sin prudencia obstaculiza a la visión abstracta y clara de los problemas reales, generó históricamente un obstáculo al planteamiento de la teoría cinético molecular de los gases.

Otro ejemplo pero en relación con el uso de analogías las presenta Bachelard en el caso de la latroquímica de Paracelso quien buscó relacionar analógicamente los astros con los metales, entre los metales y las partes del cuerpo en un triangulo universal cielo/tierra/hombre en el cual se confía para el tratamiento de las enfermedades diciendo "para cada enfermedad del hombre, cada desarmonía accidental de un órgano, el remedio apropiado resulta ser el metal que está en relación con el planeta análogo al órgano enfermo" es otro ejemplo de pensamiento precientífico.

Respecto al obstáculo animista como producto de una intuición vitalista (contraria a lo material) se funda sobre la analogía de los llamados tres reinos de la naturaleza y particularmente de la trasferencia de las propiedades a cerca de los fenómenos de la vida tanto animal como vegetal al reino mineral, bajo una creencia en el carácter universal de la vida que se da a partir de una sustancia viva que es especial y que circula a través de toda la naturaleza y que dirige a 
La imagen pública de la química y su relación con la generación de actitudes hacia la química y su aprendizaje William Manuel Mora Penagos | Diana Lineth Parga Lozano

la materia muerta. Una sustancia o un material abandona a un ser vivo en el cual residía perdiendo propiedades importantes: "la cera y la seda están en este caso: por ello ni la una ni la otra son electrizables. Llevando el razonamiento más lejos, la cera y la seda no son en efecto sino excrementos de cuerpos vivos" decía en 1781 Comte de la Cepéde. También en los siglos XVII y XVIII, nos dice Bachelard, la química y la mineralogía eran, "materia inorgánica aplicada sobre materia viva", en 1737 un autor anónimo escribía para la academia: "hay minas en las que los metales aún imperfectos se perfeccionan; y finalmente, a veces se cierran los yacimientos en los que se han encontrado materias metálicas no enteramente formadas; con el transcurrir del tiempo se encuentran en ellos minas muy ricas".

El mismo Lavoisier se vio objeto de sustancializar propiedades como la luz, el calor y la electricidad, como queda manifiesto en el libro publicado con Morveau: "Método de nomenclatura química" en 1887: la luz es una sustancia que "actúa químicamente sobre los cuerpos", esto puede comprobarse por la diferencia que presentan los mismos cuerpos a plena luz o privados de este elemento. Los primeros son en general coloreados, volátiles, inflamables; los segundos tienen las propiedades contrarias".

Los obstáculos epistemológicos por tanto no son simples dificultades ni bloqueos en el pensamiento sino inercias, costumbres o comodidades del pensamiento en el funcionamiento natural y cotidiano del cerebro y que generan "errores" como huellas y representaciones de la actividad intelectual que son previas a todo proceso de aprendizaje, por lo tanto el obstáculo es una forma de conocimiento previo que impide muchas veces construir nuevos conocimientos, que se manifiestan en gran parte como respuestas inmediatas y no reflexio- nadas a distintas situaciones. Estos obstáculos residen en el mismo pensamiento, en la cultura, en el inconsciente y en la experiencia cotidiana, por lo que también pueden ser considerados como dinamizadores de todo proceso de aprendizaje.

En general Bachelard propone la ciencia como la estética de la inteligencia, diciéndonos que una experiencia científica es una experiencia que contradice a la experiencia común, donde el conocer se trata de una actividad reflexiva en contra de un conocimiento anterior, dirigiendo al espíritu a superar una serie de prejuicios y dogmas, muchos de ellos aprendidos en la vida escolar, evolucionando de lo real a lo artificial, de lo natural a lo humano, y de la representación a la abstracción. Nos dice también que el conocimiento científico se construye y su acceso es un proceso de rejuvenecimiento espiritual de mutación brusca que ha de contradecir el pasado, es decir reelaborando las ideas preelaboradas y aprendidas indebidamente. También se puede decir que la obra de Bachelard no sólo ha generado una crítica profunda al conocimiento científico en general, sino particularmente al de la química como se puede ver en su obra: "El materialismo racional".

En el Materialismo Racional, Bachelard (1976) nos dice que "la producción de ideas y experiencias en la química contemporánea, sobrepasa la memoria, la imaginación y el poder de comprensión de un hombre", la ciencia contemporánea hace entrar al hombre en un nuevo mundo, ser un químico es ponerse en situación cultural, ocupando un lugar, un rango en una ciudad científica netamente determinada por la modernidad de la investigación". Se ha llegado a un punto de la historia en que el porvenir de la química compromete el porvenir del género humano, hasta tal punto es cierto que el destino del hombre está ligado al destino de sus pensamientos". 
La química ha sufrido en su historia grandes cambios, generando grandes reordenamientos profundos, donde si bien subsisten muchas palabras del pasado hay una variación radical de los conceptos, resulta claro que el progreso de la química moderna está condicionado por un ordenamiento de los valores de racionalidad, asociados a criterios de pureza aplicados al análisis de las sustancias coordinados con una síntesis de leyes racionales que permitieron no sólo organizar la periodicidad de los elementos sino permitir prever la síntesis de nuevas sustancias, para 1854 el gran químico Auguste Laurent, decía: "la química de hoy ha llegado a ser la ciencia de los cuerpos que no existen". Bachelar dice que "este espíritu de síntesis es meticulosamente progresivo. Solidario del espíritu científico, el espíritu de síntesis rechaza precisamente el espíritu de milagro amplificante que animaba al alquimista: deroga esa experiencia vaga de una probabilidad azarosa que constituía el dinamismo de la búsqueda alquímica y que subsiste a veces en esas utopías del espíritu científico que se forjan los filósofos. Ya no se intentan en la ciencia moderna síntesis inmediatas, síntesis fraguadas a nivel de lo dado material inmediato. Se emprenden síntesis formuladas sobre bases teóricas bien explicadas en función de la coordinación racional de dichas bases teóricas".

Bachelard (1976) cuenta que Charles Gerhardt, en 1848, reforzando su distinción entre una ciencia que transforma y una ciencia que describe, escribe: "lo repetimos, la química propiamente dicha está en las metamorfosis, en las generaciones de la materia; esto constituye su carácter fundamental. Devela en los cuerpos su origen y su fin. La física no los considera más que en tanto ellos persisten. Por esto el poder de transformación de la ciencia respecto de la materia resulta todavía aumentado, de modo tal que puede tenerse como una buena definición de la química moderna al carácter fundamental puesto de relieve por Gerhardt: la química es la ciencia de las transformaciones y de las creaciones materiales".

A diferencia del alquimismo y la latroquímica que buscaban un ordenamiento de la materia en el menor número posible de sustancias, por un lado, (agua, tierra, aire y fuego), y por otro lado, (mercurio, azufre y sal), la ciencia química por el contrario es merced al número creciente de las sustancias como se instituye cada vez más racionalmente el orden material, es decir que se pone del lado de la complejidad ordenada, es en la pluralidad y la diversidad donde la ciencia química crece. La química científica también crecerá cuando conceptos no abordados por Lavoisier como el de afinidad, se libera del concepto astronómico de afinidad.

Bachelard plantea que en todo el curso del presente de la obra de la química se muestra una dialéctica entre la búsqueda de la unidad de los fenómenos de la materia y el constante trabajo de diferenciación para formular planes de creación para sustancias nuevas, esto como camino de consolidación de la química científica.

Cuando la química científica supera el concepto de los 4 elementos aristotélicos (elementos -principios o elementos filosóficos) a favor de los elementos - materias asociados al concepto de cantidad y gracias a los principios de conservación, la noción de materia se torna objeto de investigación de los químicos y no de los filósofos, es sólo en el siglo XVIII y XIX donde la breve lista de elementos conocidos comienza a aumentar. Al cuantitativismo de la materia se opone el cualitativismo de los elementos - principios. La medida, la pureza de las sustancias conducen a materializar los elementos químicos en un contexto geométrico de las formas y las estructuras, que permite a su vez 
La imagen pública de la química y su relación con la generación de actitudes hacia la química y su aprendizaje William Manuel Mora Penagos | Diana Lineth Parga Lozano

comparar y diferenciarlos y proponer entre otras relacionar la actividad biológica a la arquitectura de las macromoléculas.

La consolidación de estas nuevas ideas también dependió de la separación de las ciencias la astrología de la astronomía, la astrología de la química, la química de la filosofía como lo plantea Manuel García Morentes. Fue necesario que las ciencias se hicieran autónomas para ayudarse mutuamente.

La dialéctica análisis / síntesis (si se quiere relacionar con el origen/ desarrollo de la química como ciencia) está relacionado con las relaciones oxidación / reducción, cualitativo / cuantitativo, homogenidad - simplicidad pureza / heterogeneidad - y síntesis diversas, como elementos dialéctico del origen de la química como disciplina. Habrá que ver la evolución de la era analítica de Lavoisier, la era del estructuralismo de Kekulé y la era de la sistemática y sincrética de Mendeleiev, fundada en cualidades químicas, y el periodo del cuadro clasificatorio moderno basado en las estructuras electrónicas. Así el nuevo reino no es el de la balanza sino el del espectroscopio. Lo nuclear se vuelve tan importante como lo electrónico.

La historia de la representación de las leyes de la composición química desde hace dos siglos, cede su lugar a la química de la síntesis fundamentada en el estudio de la forma o estructuras de las moléculas que forman la materia. Para lo que se requiere hacerse distinciones entre las nociones de fórmula, de símbolo, de esquema, modelo, de estructura, representación, de forma, de diagrama, entre otros. Ninguno de ellos es sinónimo.

Esas estructuras minúsculas y vibrantes que son las formas de las moléculas se asemejan al mundo de los cristales en su estabilidad y solidez, sin embargo se debe salir al paso a estas ideas, pues de lo que se trata es de establecer modelos abstractos de geometrías de la realidad de las estructuras y fórmulas, pero como lo dice Bachelard no podemos caer en un realismo ingenuo y suponer, por ejemplo, que el átomo es una pequeña pirámide por el hecho de plantear un modelo tetraédrico para el átomo de carbono, que es la orientación geométrica de su cuadrivalencia cuando forma la molécula de metano $\mathrm{CH}_{4^{\prime}}$ pues el átomo de carbono como tal no tiene forma tetraédrica, ni es un poliedro con caras y aristas, no es en realidad una cosa por pequeña que sea. Se opera allí como sí la forma fuera un absoluto, como si la forma fuera palpable y visible, objetiva desde todo punto de vista, como si se pudiera conocerla por descripción. La distribución angular de las valencias del carbono depende de los otros átomos (o grupos de átomos) que son ofrecidos al átomo de carbono para construir una molécula química. Se plantean nuevos problemas para el químico y en general para el que aprende esta disciplina como son las implicaciones experimentales en las que sus resultados como aproximaciones generan modelos abstractos, no rígidos ni estáticos para explicar el comportamiento de las moléculas.

A lo largo del siglo XIX se entrecruzaron los argumentos entre partidarios de la valencia invariable (en particular Kekulé) y los partidarios de la valencia variable según las circunstancias (Wutz, Frankland). Se puede tomar la cuadrivalencia del carbono como el postulado fundamental de la química orgánica y hacer así de ese hecho una especie de principio arquitectónico que organiza ese amplio sector de la química orgánica, este postulado tiene bases tanto teóricas como empíricas. La noción de valencia vendrá a ser remplazada por electrovalencia y covalencia, particularmente para entender el enlace químico desde la mecánica cuántica, es decir como apareo entre electrones de espines contrarios. G.N. 
Lewis propuso en 1916 la substitución del guión de valencia por el par de electrones. Es decir que la electrovalencia se representa con los símbolos + y -, para la covalencia se utilizarán (:) o (-) donde el guión es similar a los dos puntos que representan dos electrones compartidos, como lo propuso Robert Robinson en 1922. Pero estas nociones unidas a la idea de estabilidad energética al completar un número de electrones similar a los gases nobles no conduce a superar la idea del octeto como necesidad para entender el enlace químico, también el reemplazamiento del concepto de orbitas por orbitales volumétricos donde es posible encontrar los electrones nos conduce a reconceptualizar el carácter del electrón en el enlace.

La estructura tetraédrica del carbono, antes de la química cuántica, era una hipótesis basada en el principio de razón suficiente para la explicación de los fenómenos de valencia. Desde la teoría cuántica al perfeccionarse con el concepto de hibridación se pudo verificar esta hipótesis asociada a la teoría estereoquímica de Kekulé, experimentalmente utilizando técnicas espectrofotométricas.

Si la tetravalencia del carbono fue el primer gran descubrimiento de la química en el siglo XIX, el segundo gran descubrimiento de la química moderna, es el de la notación de las fórmulas desarrolladas, como lo planteará Charles Dufraisse en 1947 (citado por Bachelard, 1976) iniciadas por Cooper y Kekulé, siendo Cooper quien propuso las líneas de unión fijas y de allí posteriormente se propusieron las estructuras de fórmulas desarrolladas en un momento en que tanto el átomo y la molécula físicas se encontraban en cuestionamiento de su realidad y solo se aceptaban ellas desde el punto de vista químico como instrumentos de cálculo y explicación de los fenómenos estudiados por la química.
Y así podríamos llegar a la molécula como campo de estudio de la química y en especial su estructura espacial, donde la molécula, como dice Bachelard es un campo de fuerza, como un campo donde se intercambian energías, don de la energía es la verdadera unión de los átomos constituyentes, la molécula sólo subsiste traficando energía, yendo sin cesar de una estructura de energía a otra. Recibe energía del exterior, la guarda, la remite, la transforma. La molécula corresponde verdaderamente a la dialéctica de la materia y la energía, nos dice Bachelard. Podríamos decir entonces que el objeto de la química son las moléculas y en particular el cambio químico entendido como el proceso de ruptura y formación de enlaces para producir nuevas y diferentes moléculas (Mora y Parga, 2007).

\section{Más allá de la comunicación de las dos culturas: hacia una capacitación científica de los ciudadanos}

Hay dos áreas en las que creemos se debe orientar el cambio / mejoramiento de la imagen de la química y en general de las ciencias, por un lado en el plano de la cotidianidad (es decir en el saber de la imagen popular), y segundo en el plano de la educación formal, campo al cual centraremos fundamentalmente las ideas en el presente trabajo. En este sentido Romo (1998) insiste que para que la ciencia verdaderamente se abra al público, todos los adultos deben tener el acceso conveniente e inteligible al mundo de ciencia, y que todas las juventudes deben recibir una educación apropiada de la ciencia.

El periodismo científico, la sociología y la lingüística se han estado uniendo con la participación de escritores, periodistas, museólogos, artistas y comunicadores sociales de la ciencia en un movimiento en pro de permitir 
La imagen pública de la química y su relación con la generación de actitudes hacia la química y su aprendizaje William Manuel Mora Penagos | Diana Lineth Parga Lozano

superar el vacío de comunicación entre los científicos y los intelectuales de letras (conocido como las dos culturas), de tal modo que los primeros se entenderían con los segundos y así poder publicar información asequible a las masas de la sociedad. Brockman (1996) ha ido más allá proponiendo una "tercera cultura", que pretende que los científicos establezcan una comunicación directa con las audiencias o públicos, prescindiendo de intermediarios, persiguiendo no sólo difusión mediática y mercantil de los avances científicos, sino que debe ser orientada hacia una capacitación científica de los ciudadanos "alfabetización científica") que les permita participar en asuntos públicos solicitando cada vez más su participación en la toma de decisiones y en el diseño de las políticas que enfrenten, a las amenazas y temores de la tecno ciencia de la energía nuclear, la ingeniería genética, los semiconductores, el calentamiento global, los alimentos transgénicos, la clonación de embriones humanos, la radiación emitida por los teléfonos móviles, la deforestación, las dioxinas o los priones de las vacas locas; así como el inadecuado empleo de productos obtenidos con las actuales técnicas de desarrollo científico y tecnológico en química (pesticidas, insecticidas, abonos...), farmacología (antibióticos, ansiolíticos, analgésicos) o alimentación (grasas, comidas rápidas industriales...), para hacer que los medios de comunicación sean moralmente serios y responsables y contribuyan a ayudar a que los ciudadanos conozcan mejor los productos que consumen yel mejor modo de utilizarlos. Complementado esta idea es necesario citar las palabras de Carl Sagan (2002) cuando nos dice que hay cuatro razones principales para realizar un acercamiento concertado que acerque la ciencia a todos los ciudadanos: primero, para no caer en la pobreza y el atraso; segundo, alertarnos de los riesgos que las tecnologías que alteran el mundo; tercero, enseñarnos sobre nuestro contexto cósmico sobre dónde, cuándo y quiénes somos; y cuarto, inclusión de los valores democráticos concordantes con los valores de las ciencias.
Brockman (1996) nos dice que el quehacer intelectual de los científicos no puede ser reducido a la condición de saber y que debe incluir la comunicación social de sus resultados. Si la actividad de los científicos solo se dirige a presentar las definiciones de las teorías y los conceptos, difícilmente penetrará ésta en las mentes y espíritus de las personas, quedando sólo algo de ellas un campo extraño. No sólo lo "racional", lo lógico es necesario enseñar de las ciencias, se requiere comprender la manera en que se han construidos los conocimientos científicos, sus contextos, sus dificultades, la luchas entre comunidades, los sentimientos y emociones, solo así se unirá lo tradicional científico y lo humanístico. Los intelectuales de la ciencia deberían contribuir a trabajar en la producción de material de difusión de las ideas científicas no solo en textos, revistas sino también en campañas publicitarias y en las estrategias educativas de los museos de ciencias. En el anterior sentido cabe resaltar que la participación de los científicos en la divulgación científica posee una tradición establecida incluyendo a una larga lista de científicos como, por ejemplo, la química Marie Curie, los físicos Max Planck, y Albert Eistein, los astrofísico Stephen Hawkins y Carl Sagan, el bioquímico Isaac Asimov, y el paleontólogo y Biólogo evolutivo Stephen Jay Gould entre otros, quienes nos mostraron con sus libros una manera de difusión sus conocimientos al no iniciado en ciencias, una manera de comunicar sin generar fronteras insalvables entre quienes hacen ciencias y los legos que buscan ser más sabios y humanos en un campo como el científico en el que no sólo es conocimiento o cultura, sino también poder (económico, industrial, político, militar, etc.) (Chudnovsky, Tejada, Punset, 2008).

Martín (2003) dice que podrían haber dos ventajas principales de los científicos a la hora de realizar divulgación científica, 
por un lado, sería un mayor conocimiento del contacto con la empresa científica y sus métodos y normas prácticas, además de un conocimiento especializado sobre determinados campos del saber científico. Este último punto facilitaría la comprensión de las fuentes y el proceso de "traducción" y explicación de los conocimientos científicos. Este mismo autor (Martín, 2003) nos dice que en los últimos años, ha emergido de una intelectualidad científica que investiga, y a través de su propia obra, difunde las cuestiones más importantes de nuestros días conectado el público directamente, sin intermediarios. Entre los iniciadores del estilo sobresalen Watson y "La doble helice", Monod y "El azar y la necesidad", y Jacob y "La estatua interior". Y más recientes: Rachel Carson y "Primavera Silenciosa"; Penrose y "La nueva mente del emperador"; Gell-Mann y "El quark y el jaguar"; Dawkins y "El gen egoísta", "El relojero ciego" y "Destejiendo el arco iris"; Gould y "El dedo pulgar del panda", "La sonrisa del flamingo", y "La vida maraviIlosa"; Margulis y "Microcosmos"; Davis y "Los Mitos de la materia"; Prigogine y "El fin de las certidumbres"; Shttuck y "Conocimiento prohibido"; Silver y "Vuelta al Edén"; Leakey y Lewin con "La sexta extinción"; Allen Paulos y "Un matemático lee periódico", y "Érase una vez un número", y finalmente, Wilson y "La unidad del conocimiento".

Fundamentados en Moreno, (2001) es posible proponer una serie de elementos generales orientados al cambio de actitud ante la imagen pública:

- Un esfuerzo, por parte de la comunidad científica, para explicar y divulgar los resultados de su actividad, y en contrapartida, un reconocimiento, por el momento casi inexistente, de esta labor.

- Aumentar la comunicación entre la sociedad y la comunidad científica.
- Enseñar a pensar. Intentar inculcar la metodología científica y el espíritu crítico, racional y escéptico para afrontar los problemas. Una vía para ello podría ser:

- Producir series y filmes donde se refleje el potencial de las métodologías científicas, como proponía el científico y divulgador Carl Sagan.

- Realizar documentales menos aburridos, donde la imaginación esté al servicio de la divulgación científica. Rigor y amenidad no tienen por qué ser antagonistas.

- Exigir, como espectadores, una mayor rigurosidad en las puestas en escena. Mostrar los laboratorios y el trabajo científico tal como son (en grupos multidisciplinares, como por ejemplo en el filme Marte rojo (2000)), abriendo la caja negra de las ciencias como diría Woolgar (1991).

- Presentar la ciencia no como dogma o un cuerpo de conocimientos inamovible, sino como lo que es: una aventura del pensamiento de la que todos los ciudadanos debemos ser partícipes.

- Abrir los debates sobre los grandes temas tecnocientíficos (bioética, medio ambiente) a la sociedad. Una sociedad bien informada puede y debe aportar su opinión (Bernal, 1978).

- Superación de las dos culturas. En universidades eminentemente técnicas, las asignaturas de corte humanístico deberían convivir con las materias tecnocientíficas tradicionales. Pero esta saludable combinación entre humanidades y ciencia, elementos inseparables de la cultura, ¿se da también en las carreras de letras? Si no es así, debe realizarse un esfuerzo en este sentido. 
La imagen pública de la química y su relación con la generación de actitudes hacia la química y su aprendizaje William Manuel Mora Penagos | Diana Lineth Parga Lozano

\section{Las investigaciones en el contexto pedagógico/didáctico de la imagen de la química}

En un trabajo anterior Mora (1997) destaca tres imágenes acerca de las ciencias, donde la química es el caso prototípico: imagen académica (producida por científicos y filósofos), una imagen escolar (encontrada en los textos escolares y del trabajo del profesorado en las aulas de clase) y un imagen popular generada en la interacción cotidiana de las personas con los medios de comunicación.

Respecto a la imagen académica podríamos decir que son dos visiones las que principalmente circulan. La primera, producto del empirismo radical que sobre valora la observación libre de teorías y de un método científico inductivo y rígido que va de la observación a las teorías (que para sorpresa es compartida aún por un buen número de trabajadores de las ciencias y profesores en todos los niveles); y la segunda producto de una exagerada y rigurosa racionalidad proyectada por la comunidad científica, que fue forjada principalmente por los éxitos de la física en los últimos 100 años, y que ha sido aceptada por una buena parte de filósofos de las ciencias hasta mediados del siglo XX. Es decir que, por un lado, el quehacer de los científicos se entiende como un estereotipo no histórico del desarrollo de las ciencias producto de acumulación de conceptos y teorías; y por otro lado se sobrevalora la ciencia como única fuente racional de conocimiento reduciendo las demás formas culturales a simples supercherías. Sin embargo, existen evidencias que muestran que muchos investigadores en ciencias al igual que buena parte de los docentes, tienen una visión filosófica sobre las ciencias bastante simple, que no aportan en mucho a describir una ciencia adecuada en los estudiantes, esto debido posiblemente a que la ciencia de nuestro siglo se ha ramificado tanto y ha llegado tan lejos, que su progreso requiere una enorme especialización de sus practicantes que lo hace ignorante en muchos otros campos como la historia y la filosofía. Como dice el filósofo Jesús Mosterin (2003) "el especialista cada vez tiene que especializarse más, con lo que sabe cada vez más sobre cada vez menos, hasta que llega a saberlo casi todo sobre casi nada". De otro lado, lo cierto es que el profesor en general, muchas veces muestra mínimo interés por participar en la reflexión sobre la naturaleza de las ciencias y la divulgación científica. Dado que la ciencia ha sufrido una especialización sin precedentes, tiende a pensarse que sólo se está capacitado para realizar un par de artículos o conferencias sobre su campo concreto de estudio y que se perdería rigurosidad si trata otros temas, menospreciando la formación general humanística que ha recibido.

La imagen escolar que circula en las aulas producto de algunos currículos enciclopedistas y estrategias de enseñanza transmisionistas (confunde resolución de problemas con ejercicios mecánicos y algorítmicos; los trabajos prácticos de laboratorio con experimentos; y evaluación con calificación) que tienen como única fuente de saber los libros de texto, hacen ver el conocimiento científico como verdades que hay que memorizar, como producto del uso del mal llamado "método científico" es decir, como fórmula única y fidedigna (que parte de la observación para llegar a las teorías), lo que ha reforzado la imagen de las ciencias y de la química como instituciones "religiosas" poseedoras de un conocimiento superior; descubridora y acumuladora de conocimientos "verdaderos" que nunca son modificados o cambiados; parece estar mas ajustado al modelo de las épocas de los siglos del oscurantismo medieval propios de los dogmas del mal aristotelismo y de la fe religiosa, de las verdades incontrovertibles, como fuente del conocimiento, de 
la tradición y las revelaciones sobre la experimentación y la reflexión crítica del conocimiento. Las encuestas realizadas acerca de cómo son vistos los científicos, en este marco educativo, por diferentes estudiantes y personas del común, arrojan las misma conclusión: los científicos serían exclusivamente hombres, maduros o mayores, calvos o con cabellos a lo Einstein, trabajan aislados en laboratorios lúgubres y apartados, en temas secretos o peligrosos. Además de su presencia como elemento perturbador o generador de problemas, por lo que su habilidad para afrontar y resolver los mismos parece ir de mal en peor.

En la imagen popular de la química que se maneja en el ciudadano común y corriente (o ciudadano de a pie), se caracteriza por entender los conocimientos científicos como estrategia de persuasión formados por una fuerte influencia brindada por los medios de comunicación; así las propagandas que aparecen en televisión, en lugar de optar por el uso de la crítica y el respeto, avasallan al televidente desacreditando los productos de la competencia, enmascarados por la reputación de una falsa ciencia; así la eficacia de un detergente o de un método de adelgazamiento queda absolutamente garantizado con el contundente adjetivo "científico" o en otras palabras "respaldado científicamente por la universidad tal", todo lo anterior unido a la vulgarización y tergiversación de los aportes científicos, así imprudentemente se oye decir: "la química del amor nos unió", "alimento sano, libre de química". Una serie televisiva (o los mensajes en periódicos, revistas, y radio) es más decisiva para cambiar actitudes, valores y representaciones acerca del conocimiento y las ciencias que la mayoría de los programas curriculares que se ofrecen en las instituciones educativas. Esta imagen negativa de la química no sólo está presente en la sociedad sino también en nuestros estudiantes que aunque no renuncian a disfrutar de los avances que ha supuesto esta actividad científica la miran con cierta desconfianza. Es frecuente escuchar opiniones acerca de las implicaciones de la química en el medio natural y social tales como: "estos productos tienen mucha química", "medicamentos naturales libres de químicos", "son pura química y no son tan buenos para la salud"; o bien "no me gusta vivir en esa ciudad porque hay muchas industrias químicas". Lo cual indica que la industria química y la propia química se asocian preferentemente con los efectos contaminantes y el deterioro en el medio ambiente, sin tener presente que esas mismas industrias abastecen de productos que sirven para cubrir nuestras necesidades personales y sociales.

Estas imágenes, también han sido reportadas en trabajos publicados en revistas especializadas en enseñanza de las ciencias (Hodson, 1985; Gil, 1993; Giordán, 1988; Mellado, 1993; Luffiego, 1994) distando de lo que muchos estudiosos en filosofía, historia, psicología y didáctica de la química querrían de esta ciencia para una formación de las nuevas generaciones no sólo de futuros químicos sino de una sociedad mejor alfabetizada en ciencias. Por el contrario, el desarrollo de las ciencias, mostrada por historiadores y epistemólogos particularmente de la segunda mitad del siglo XX que han involucrado categorías sociales a sus propuestas, permite entender que ellas no crecen de una manera lineal acumulativa, que no se puede pensar que nuestro conocimiento llegará a ser eventualmente completo, ni que exista un único método científico, sino más bien cada ciencia tiene sus procedimientos particulares que evolucionan a la par con ellas y permitiendo, a su vez, que distintas formas culturales adopten criterios científicos en sus desempeños y que sean considerados como igualmente valiosos para el desarrollo de las sociedades, superando el mito racionalista de la conciencia objetiva e infalible de la verdad científica como único conocimiento humano admisible. 
La imagen pública de la química y su relación con la generación de actitudes hacia la química y su aprendizaje William Manuel Mora Penagos | Diana Lineth Parga Lozano

Si la ciencia y la tecnología, y la química como ejemplo, son el núcleo esencial de la civilización actual, ¿cómo es que ocupan un lugar tan secundario y subordinado en la cultura de nuestro tiempo? Y si la historia, la epistemología, la psicología, y la sociología de las ciencias son un camino para reflexionar, ¿cómo es que se pone tan poca atención a estas disciplinas en la educación científica en las aulas de clase y en la información de las ciencias que llega al ciudadano común?

\section{Generación de actitudes hacia las ciencias y hacia la química en el contexto escolar}

Para despertar el interés por la ciencia en el alumnado, se requiere que conozca su valor social y cultural, para así generar actitudes que le permitan valorar el papel que la ciencia juega y ha jugado en la sociedad y en nuestras vidas. Debe ser claro, después de todo lo dicho, que la imagen que se tiene sobre la química y en general sobre las ciencias deberían generar a su vez una serie de actitudes propias de la dimensión afectiva de los aprendizajes que pueden ser negativas o positivas. Por lo que aquí respecta creemos que imágenes negativas de las ciencias generarán actitudes negativas (Mora, 1997).

Las investigaciones en el campo de las actitudes de los estudiantes hacia las ciencias, y en particular, hacia la química, han puesto de manifiesto (Shrigley y Jhonson, 1974; Schibecci, 1984; Yagery Penich, 1986; Romo, 1998):

- Una disminución del interés hacia las mismas a medida que pasan los años de escolarización.

- Los alumnos no piensan que los estudios de ciencias sean útiles, es decir, ellos sienten que los contenidos estudiados no tienen nada que ver con la vida diaria.
- Cuando eligen las ciencias o la química, no lo hacen por estar interesados en ellas.

- Los estudiantes tienen construida una imagen del aprendizaje científico y de los científicos estereotipada y distorsionada debido a una clara influencia del medio social del estudiante.

- Se presenta un estereotipo de la masculinidad de la ciencia que continúa tanto en los niveles medios como en los superiores.

- La química y sus aplicaciones tecnológicas presenta una imagen pública negativa. Los temas de gran impacto social y medio ambiental son los que interesan más a los estudiantes y a los que se suelen referir cuando se les pide su opinión respecto de los temas que ellos elegirían para una clase de ciencias.

La investigación didáctica respecto al papel del profesorado y de los currículos, en la generación de actitudes hacia las ciencias, han mostrado que (Furió y Gil, 1989; Gil, 1991; Porlán, 1998):

- El profesorado tiene gran relevancia en el proceso de formación actitudinal y el propio alumnado percibe cómo su profesor puede influir en la generación de interés hacia la disciplina que éste enseña. Es decir, el profesor es uno de los principales impulsores de la formación de actitudes hacia la química y su aprendizaje.

- Los contenidos actitudinales muchas veces son ignorados tanto por el profesorado como por el estudiantado, prestando más atención a los contenidos conceptuales y procedimientos y menos a las actitudes.

- Es frecuente entre los profesores el pensar que las disciplinas científicas como 
la química son difíciles y no están al alcance de todo el mundo. De ahí que se acepte como "natural" el fracaso de un porcentaje significativo de estudiantes.

- Existe una concepción muy extendida entre el profesorado sobre el carácter inductivista de la naturaleza de la metodología científica, ignorando las aportaciones de la epistemología moderna.

- El profesorado reconoce la importancia vital de la motivación y las actitudes como motores que impulsan el aprendizaje de las ciencias pero, una vez en el aula, se "olvidan" de ellas.

- Los cursos de la ciencia escolares normalmente descuidan (o tratan superficialmente) la naturaleza de ciencia.

Parece razonable, después de los antecedentes mostrados, pensar en la necesidad de una mejor formación tanto inicial como permanente de los profesores de ciencias y de todos aquellos que de una u otra forma participan de los procesos educativos principalmente en la escuela. Un camino que parecería obvio, en el cambio de imagen de la naturaleza de las ciencias, sería participar de cursos de epistemología e historia de las ciencias, pero aunque esto es muy importante, de igual manera e importancia es el trabajo de reflexión en equipos particularmente en torno al tipo de imagen que se ofrece en las estrategias didácticas que se ejecutan en clase.

La nueva imagen de la naturaleza y evolución del conocimiento científico se han venido plasmando en diversas corrientes epistemológicas, que están más en consonancia con los valores de una nueva civilización pluricultural. Los epistemólogos en sus intentos de dar explicación a la manera como cambian las ciencias, han dado un buen contenido que ha generado implicaciones en el campo didáctico, no solo en la desmitificación de las características propias de las actividades científicas sino sugerir estrategias para el cambio conceptual de los alumnos. En este momento sólo nos dedicaremos a los aportes en la desmitificación de la imagen de las ciencias:

Rechazo del inductivismo - empirismo y reafirmación de la importancia de aspectos tales como el conocimiento, delimitación y contextualización de los problemas en un marco teórico, la formulación de hipótesis, diseños experimentales, etc., de esta manera se permite la superación del concepto de observación y experimentación aséptica o libre de teorías. Así mismo la superación de la idea de que el conocimiento ya existe o que hay que descubrirlo a través de los sentidos. Más bien el conocimiento se construye y por tanto es sujeto de modificaciones históricas.

Las teorías científicas no son sustituidas simplemente porque sus hipótesis puedan ser refutadas experimentalmente, sino que la historia de las ciencias puede ser descrita en términos de competencia entre programas de investigación alternativos, entendiendo por programa de investigación una serie de teorías unidas por su evolución, que permite explicar con éxito nuevos hechos.

La necesidad de cuestionar el papel de la ciencia como camino de alcanzar la "verdad" y cómo única forma de conocimiento válido socialmente. Por el contrario, se establece la ciencia como empresa humana, caracterizada por el trabajo de colectivos con las limitaciones y virtudes del pensamiento humano, contextulizándola en momentos históricos específicos que dependen de factores físicos, políticos e ideológicos. 
La imagen pública de la química y su relación con la generación de actitudes hacia la química y su aprendizaje William Manuel Mora Penagos | Diana Lineth Parga Lozano

Romo (1998) muestra que los estudiantes de secundaria no tienen actitudes muy positivas hacia la química y su aprendizaje porque principalmente el pensamiento espontáneo docente acerca del currículum de química (finalidades, objetivos, contenidos y estrategias didácticas) no tiene en cuenta la dimensión afectiva del aprendizaje, tal como lo muestra en las siguientes conclusiones en su tesis doctoral:

- Los estudiantes encuestados muestran una imagen moderadamente negativa de la química, la cual no es tan bien valorada respecto de las otras asignaturas, relacionando la química con las consecuencias más negativas del desarrollo tecnológico. Son menos valorados aspectos sociales de la química mayoritariamente influencias a lo largo de la historia y particularmente sus implicaciones para el medio ambiente.

- Al valorar las finalidades de la química los estudiantes piensan que su adquisición es necesaria para la promoción posterior a estudios superiores, aunque no conocen en su mayor parte la utilidad de la química, debido posiblemente a que en las enseñanzas habituales son poco abordados estos temas.

- El pensamiento espontáneo docente sobre el currículum es reduccionista al considerar que las finalidades y objetivos únicos son el de aprender los contenidos conceptuales de la química de este nivel. Se tienen poco en cuenta los objetivos procedimentales y actitudinales.

- Respecto a las características de la química que van a enseñar, en general tienen visiones cercanas a las concepciones empiristas y elitistas de la ciencia y el desarrollo científico y son más acentuadas en el caso de los profesores en activo que en el de los profe- sores en formación, probablemente por la formación ambiental y la práctica docente de los primeros.

- Los contenidos del currículum, tratados en los cursos de química en los Sistemas Educativos tanto de España como de México $y$, en particular los textos, no muestran una imagen de la química en relación con el mundo real, ni tienen en cuenta aquellos aspectos actitudinales de relación CTS, muestran la imagen de la química descontextualizada en lo social, sin tener en cuenta los aspectos históricos.

Creemos que formación docente unido a reformas curriculares adecuadas y una distinta forma de interacción en la comunicación de los medios en la que participen directamente quienes trabajan en la ciencia y reflexionan sobre ellas es clave para cambiar la imagen y las actitudes hacia las ciencias y hacia la química, que serán clave en los procesos de alfabetización científica que permitan una educación científica para la toma de decisiones acerca de los problemas a los que se enfrenta la humanidad, la formación de un espíritu crítico, y el disfrute personal de sorprenderse y maravillarse (Gil y Vilches, 2004). Pero como apunta Cañal (2004) hay que estar alertas y salir al paso a obstáculos claves en la alfabetización científica: la falta de trabajo por niveles de alfabetización científica (en el nivel práctico de la vida cotidiana; en el nivel cívico que permite la participación en el debate social y las decisiones políticas; el nivel cultural que permita reflexionar sobre la incidencia de la ciencia y la tecnología en la configuración y dinámica social; se unirían otros dos niveles el funcional y el académico para usar los conocimientos escolares relativos a las ciencias); cambio en la enseñanza de las ciencias y la formación del profesorado (que permita establecer prioridades curriculares 
en las distintas etapas de la educación, cambios en los contenidos, en las estrategias de enseñanza, y la formación permanente de los docentes), el arraigo del pensamiento irracional (que aceptan las profecías de adivinos, el poder de la suerte, las maldiciones, los conjuros, y los mitos y tabús que intentan remplazar la ciencia).

\section{Aparición de propuestas curriculares como respuesta a las preocupaciones por la imagen negativa hacia la química}

El currículum ha de conformar creencias, actitudes y valores que, fundamentalmente, desarrollen un interés crítico por la actividad científica. Actitudes y valores que les permitan valorar el papel que la ciencia juega y ha jugado en nuestras vidas y preparen así el camino para que, en un futuro próximo, estos estudiantes puedan participar colectivamente en la solución de los problemas con los que se enfrenta la sociedad de la que forman parte.

En los últimos años se vienen reclamando insistentemente una educación científica y tecnológica con características más humanistas, basada en la necesidad de desarrollar una comprensión pública de la ciencia y la tecnología. En este ambiente social emerge la educación CTS (Ciencia, Tecnología y Sociedad) (González, López, y Luján, 2000) como una innovación del currículo escolar de carácter general, que proporciona a las propuestas de alfabetización en ciencia y tecnología (Science and Technology Literacy, STL) para todas las personas (Science and Technology for All, STA) una determinada visión centrada en la formación de actitudes, valores y normas de comportamiento respecto a la intervención de la ciencia y la tecnología en la sociedad (y viceversa) con el fin de ejercer responsablemente como ciudadanos y tomar decisiones razonadas y democráticas en la sociedad civil. Desde este punto de vista, CTS es una opción educativa transversal, que da prioridad, sobre todo, a los contenidos actitudinales (cognitivos, afectivos y valorativos) y axiológicos (valores y normas) (Acevedo, Vásquez, y Manassero, 2002). Los estudios de Ciencia, Tecnología, Sociedad e Innovación (CTS+l) constituyen un campo de trabajo interdisciplinar en educación, investigación y política pública, que se centra en los aspectos sociales de la ciencia y la tecnología, tanto en lo que concierne a sus condiciones sociales como en lo que atañe a sus consecuencias sociales, políticas, económicas, éticas y ambientales.

La preocupación por este analfabetismo ha dado origen a varios proyectos, sobre todo en Estados Unidos y no es ninguna casualidad que la "educación científica para todos" se haya convertido en muchos países del mundo en un eslogan para la reforma y la innovación del currículum de ciencias (AAAS, 1989). Junto con la educación tecnológica formó el tema del fórum internacional Educación 2000+ (Holbrook, 1998), celebrado en 1993, bajo los auspicios de la Unesco (Jenkins, 1999). Cabe afirmar que algunas de las iniciativas asociadas con el movimiento Science, Technology and Society (STS) representan un intento por situar la ciencia en el ámbito de la acción práctica o de la participación en las decisiones frente a problemas sociales y ambientales (Mora y Parga, 2005b).

Acevedo, Vásquez y Manassero (2002) sostienen que existe una fuerte red CTS alrededor del mundo que crece y se consolida, dando apoyo y estableciendo una base firme para implantar de manera general este campo de estudios e investigación. Ade- 
La imagen pública de la química y su relación con la generación de actitudes hacia la química y su aprendizaje William Manuel Mora Penagos | Diana Lineth Parga Lozano

más, a partir de finales de los años setenta se incorporaron los estudios sobre el medio ambiente, dando lugar a los denominados programas STES (Science/Technology/ Environment/Society) y, en la década de los ochenta, el movimiento feminista empezó a ocuparse de las ciencias, abordando investigaciones que unen los estudios sociales de la ciencia con la teoría feminista, ya que los primeros no habían considerado la cuestión del género como una categoría de análisis y la segunda tan sólo se había ocupado de la ciencia de una forma tangencial. Este enfoque feminista radical generó los programas STGS (Science/Technology/Gender/Society).

Acevedo, Vásquez y Manassero (2002) citando a Bybee (1985) comentan que la educación CTS debe equilibrar tres tipos de objetivos:

- conocimientos para fines personales, ciudadanos o culturales y destrezas de aprendizaje,

- investigación científica y tecnológica para recoger información, resolver problemas y tomar decisiones $y$

- desarrollo de valores, a través de las interacciones CTS, para temas públicos y políticos, locales o mundiales.

Otras referencias han adoptado variantes diversas para definir los objetivos de esta corriente. Por ejemplo, las siguientes se han expresado en los Estados Unidos:

- Preparar a los estudiantes para usar la ciencia y la tecnología en el entendimiento y mejoramiento de su vida diaria.

- Aplicar el conocimiento científico en la vida cotidiana; e introducir las implicaciones sociales y ambientales del desarrollo científico y tecnológico.
- Utilizar los aspectos y problemas sociales para lograr satisfacer las necesidades de nuestra sociedad y nuestros estudiantes.

- Hacer énfasis en todos los niveles sobre la relevancia social y humana de la química.

- Ayudar a los estudiantes a mejorar en pensamiento crítico, razonamiento lógico, resolución creativa de problemas y toma de decisiones.

Garritz (1994) señala que la National Science Teachers Association (NSTA) de los Estados Unidos ha definido al enfoque ciencia-tecnología-sociedad (CTS) como la enseñanza y el aprendizaje de la ciencia en el contexto de la experiencia humana. CTS es una reforma educativa que implica un cambio de gran alcance en el que los contenidos conceptuales tradicionales cambian su sentido y en cierta forma pierden su importancia relativa, por lo que el medio social y ambiental resultan ser lo más relevante. Para Yager (1992), lo que resulta esencial en el enfoque CTS es el dedicar esfuerzos para formar ciudadanos informados que sean capaces de tomar decisiones cruciales sobre problemas y asuntos actuales, y de emprender acciones personales derivadas de tales decisiones.

Algunos proyectos de currículos para la enseñanza - aprendizaje de la química (Garritz, 1994; Orlik, 2002; Mora y Parga, 2008) son los siguientes:

- Proyecto SALTERS de la Universidad de York en Inglaterra (Burton, Holman, Pilling, and Waddington, 1995): diseñado para el nivel secundario. Organizado en dos partes: la primera para entre 13 y 16 años, y la segunda entre 16 y 19 años. El objetivo fundamental es el de aprender química que permitan 
vivir y trabajar en una sociedad científico tecnológica. El curso Salters consta de 16 módulos: Vestido, bebidas, comida, metales, calor, transporte de productos químicos, construcción, procesamiento de comida, aseo, minerales, plásticos, combustión y enlaces químicos, energía, lucha contra las enfermedades, utilizando electricidad.

- Science and Technology in Society (SATIS) del Reino Unido: Promovido por la Asociación de Educación de la Ciencia (ASE), el proyecto SATIS inició en 1984. Sus primeras publicaciones aparecieron en 1986, dirigidas a las edades de 14 a 16 años. En septiembre de 1987 inicia el proyecto SATIS 16-19, que publicó 100 unidades hasta 1991. Las habilidades especiales que se busca formar en los estudiantes se refieren, en general, a: capacidades personales (capacidad de autocalificar el desempeño), habilidad numérica (capacidad de entender e interpretar datos numéricos), resolución de problemas (capacidad de reconocer y definir la naturaleza de un problema dado), comunicación (capacidad de presentar información), tecnología informática (capacidad de manejar computadoras). Temas tratados: el aire que respiramos, protegiendo la capa de ozono, problemas petroquímicos, ayudando a los asmáticos, convertidores catalíticos, ganado y productos químicos, energía solar, la ciencia como una empresa humana, blanqueado con cloro, la industria de los perfumes, medicinas sobre el mostrador, poliuretanos, neutralizando la lluvia ácida, metales bíblicos (Garritz, 1994).

- Chemistry and the Community (ChemCom), de la American Chemical Society (1998): Química en la comunidad, desarrollado por la American Chemical Society
(ACS, 1988; Sutman y Matthew, 1992), por ejemplo, es "un curso de química de un año de duración, diseñado para el estudiante universitario, no técnico, y para el estudiante brillante que no tiene intención de ingresar en la universidad", estudiantes de la preparatoria (grados 10 a 12). El curso principales: tomar decisiones y resolver problemas (Orlik, 2002), tiene dos enfoques: procura resaltar la aplicación, antes que la generación del conocimiento químico, y destacar la ciencia en la comunidad, antes que en el banco del laboratorio, reflejando un compromiso con estrategias de aprendizaje cooperativo, centradas en el estudiante, como la representación de papeles, encuestas, entrevistas y debates, y cada unidad del curso hace participar a los estudiantes en actividades que suponen tener que tomar decisiones. La acción o "capacidad" práctica, depende fuertemente del contexto, que no es disciplinar, lo que se muestra muy sensible a la base disponible de conocimientos y es rica en valores en cada momento. Resulta interesante que la mayor crítica sobre ChemCom haya venido en la dirección de los propios profesores, quienes calificaron a la primera edición de 1988 de ser un proyecto más bien de divulgación, que reduce al mínimo la información química que todo bachiller de ciencias debe conocer. Los títulos de las unidades de ChemCom son: logrando nuestras necesidades de agua, conservando los recursos químicos, Petróleo ¿para construir? ¿para quemar?, entendiendo la alimentación, química nuclear, aire y clima, salud sus riesgos y oportunidades, la industria química (Garritz, 1994).

- "Scope, Sequence and Coordination" (SS\&C), de la NSTA, y el Proyecto 2061 de la AAAS: La National Science Teachers Association reunió en su proyecto "Scope, Sequence and Coordination" un conjunto básico curricular para la ense- 
La imagen pública de la química y su relación con la generación de actitudes hacia la química y su aprendizaje William Manuel Mora Penagos | Diana Lineth Parga Lozano

ñanza integrada de las ciencias (biología, química, ciencias de la Tierra y del espacio, y Física para los seis años del bachillerato) y ha elaborado un conjunto de textos y materiales para llevarlo a cabo. La prueba recorrió cientos de escuelas secundarias desde Alaska hasta Puerto Rico. Este proyecto presenta una estructura educativa novedosa que pretende reformar toda la vida escolar, basada en una visión integral del conocimiento (la conexión de humanidades, artes y ciencia) y el uso de medios informáticos para la enseñanza. El National Research Council de los Estados Unidos insistió en la bondad de integrar un conjunto de estándares nacionales para la educación científica y matemática.

- Química del Consumidor, de Carl Snyder: Este es un esfuerzo interesante que nació hace 20 años en la Universidad de Miami. El curso fue dirigido inicialmente a alumnos de ciencias sociales, humanidades $y$ artes, e intentó mostrar la química y sus principios a través de sus aplicaciones en los productos para el consumidor. Este proyecto evolucionó en un texto reciente que muestra la química de las sustancias de nuestro mundo cotidiano, de lo trivial a lo polémico, de la sal de mesa a las drogas de abuso y sus efectos, del agua potable a la energía nuclear. Se abordan asuntos sobre seguridad, el significado y medición de la contaminación, y particularmente sobre la ambigüedad de los términos 'bueno y malo' aplicados a productos y procesos químicos. El objetivo es llevar a los estudiantes hacia el dominio de la química, no sólo por la conciencia de que como seres humanos somos una fábrica de productos químicos, sino además para mostrar que podemos y debemos tener la posibilidad de elegir cómo usamos los productos químicos de nuestro universo.
- CEPUP: Chemical Education for Public Understanding Program, Lawrence Hall of Science (Berkeley): Programa desarrollado en la Universidad de California, cuyo enfoque es eminentemente experimental y relacionado estrechamente con problemas sociales contemporáneos, dedicado a la enseñanza de la química en el nivel elemental.

- Chemestry in Context (Nentwig, and Demuth, 2007): diseñado para estudiantes de primeros cursos de universidad, como curso no introductoria para especialistas no químicos, con una duración de dos años. Están planeados alrededor de asuntos sociales importantes en los cuales la química tiene mayor impacto: problemas del ozono, alimentación drogas, calentamiento global, etc. Este curso cuenta con ayudas audiovisuales como doce videos, y manuales para el docente.

\section{Conclusiones}

En este artículo se ha tratado de mostrar que la imagen popular y escolar de la química no es positiva, lo que ha generado actitudes negativas hacia su aprendizaje y dificultades fundamentales en los procesos de alfabetización social en ciencias y tecnología. Se requiere superar la imagen de la química como ciencia de afectos contrarios, producto del impacto de los medios de comunicación, y de sus históricas e inadecuadas relaciones con la religión y la enseñanza, que han mostrado una visión ambivalente y conflictiva de la química como productora de grandes conocimientos y avances a favor de la humanidad pero al mismo tiempo deterioradora del medio ambiente y causante de serios riesgos para la continuidad de la especie humana en el planeta Tierra. 
Plantear un cambio en la imagen social de la química, tanto en los medios de comunicación como en el contexto escolar, requiere de distintas estrategias complementarias, que parten de la reclamación para que los científicos que producen el conocimiento de la química se interesen por su divulgación de masas para todos los no expertos, y por otro lado de una mayor articulación de la cultura tecno científica con la cultura socio humanística en las propuestas curriculares formativas en las instituciones escolares.

Una la línea de investigación denominada Public Understanding of Science (y liderada por una revista con el mismo nombre), pretende configurar un acercamiento de comunicación entre el conocimiento científico a las masas de la sociedad; y por otro lado, las investigaciones en filosofía e historia de la química, como las presentadas en revistas como HYLE (International Journal for Philosophy of Chemistry), Isis y Osiris (Historia de la Química), contribuyen a las investigaciones en didáctica de la química (y socializadas en distintas revistas internacionales como Journal of Chemical Education, Chemestry Education, Science \& Education, TED, Educación Química, Alambique, etc.) a generar propuestas de formación docente centradas en diseños curriculares y organización de contenidos (por ejemplo dese la perspectiva (TS-A) más acordes a la generación de actitudes hacia la química y su aprendizaje, fundamentado en la integración del conocimiento disciplinar, metadisciplinar, psico pedagógico y del contexto (Mora y Parga, 2008) para así mostrar una imagen más constructivista y que permita entender el contexto de la producción de los conocimientos abriendo la caja negra de la química a los aspectos sociales y aportando de esta manera a mejores propuestas de enseñanza desde la didáctica de la química.

\section{Referencias bibliográficas}

AAAS: American Association for the Advancement of Science. (1989). Science for All Americans Online. (Traducción al Español: (2000). Ciencia: Conocimiento Para Todos. Proyecto 2061. http://www.project2061.org/esp/tools/sfaaol/chap1. htm\#sci

Acevedo, J.A., Vásquez, A., y Manassero, M.A. (2002). El movimiento ciencia - tecnología - sociedad y la enseñanza de las ciencias. Disponible [On - line] en Sala de Lecturas CTS+l de la OEI, http://www.campus-oei. org/salactsi/acevedo13.htm

American Chemical Society. (1998). QuimCom. Química en la Comunidad. México: Addison Wesley Logman - Pearson.

Artigas, M. (1995). La religión ante el progreso científico. En torno a un libroencuesta de José María Gironella. Universidad de Navarra. Facultad de Ciencias y Eclesiástica de Filosofía. Grupo de Investigación sobre Ciencia, Razón y Fe (CRYF). Aceprensa, 12/95. Disponible [On - line] en http://www.unav.es/cryf/ religionanteprogresocientifico.html

Appleyard, B. (2004). Ciencia vs Humanismo. Un desacuerdo Imprevisible. Buenos Aires (Argentina): Editorial el Ateneo.

Astolfi, J. P. (2003). Conceptos Clave en la Didáctica de las Disciplinas. Sevilla: Diada Editora.

Bachelard, G. (1976). El Materialismo Racional. Buenos Aires: Editorial Paidos.

Bachelard, G. (1978). La Formación del Espíritu Científico. Buenos Aires: Siglo XXI Editores. 
La imagen pública de la química y su relación con la generación de actitudes hacia la química y su aprendizaje William Manuel Mora Penagos | Diana Lineth Parga Lozano

Bernal, J. (1979). La Ciencia en Nuestro Tiempo. México: Editorial Nueva Imagen.

Böschen, S.; Lenoir, D.; Scheringer, M. (2003). Sustainable chemistry: starting points and prospects. Naturwissenschaften (2003) 90:93-102

Brockman, J. (1996). La Tercera Cultura. Barcelona: Tusquets Editores.

Burton, W. G. Holman, J. S. Pilling, G. M. and Waddington, D. J. (1995). Salters Advanced Chemistry. A Revolution in Pre-College Chemistry. Journal of Chemical Education. Volume 72 Number 3 March 1995.

Cañal, P. (2004). La alfabetización científica: ¿necesidad o utopía? Cultura y Educación, 16 (3), 259-272.

Chudnovsky, E., Tejada, J., Punset, E. (2008). El Templo de la Ciencia. Los Científicos y sus Creencias. Barcelona: Ediciones Destino S.A.

Dampier, C. (1986). Historia de la Ciencia y sus relaciones con la Filosofía y la Religión. Madrid: Editorial Tecnos S.A.

Fernández - Rañada, A. (2008). Los Científicos y Dios. Madrid: Editorial Trotta S.A.

Furio, C.M. y Gil, P.D. (1989). La Didáctica de las Ciencias en la Formación Inicial del Profesorado: Una Orientación y un programa teóricamente fundamentados. Enseñanza de las Ciencias. 7 (3). pp 257-265.

Garritz, A. (1994). Ciencia - tecnología sociedad: A diez años de iniciada la corriente. Aportaciones y opiniones sobre la enseñanza de la química en el nivel medio superior. Disponible [On line] en Sala de Lecturas CTS+I de la OEI, http://www.campus-oei.org/salactsi/ quimica.htm
Gil, D., (1991). Técnicas y Experiencias Innovadoras en la Enseñanza de las Ciencias. Enseñanza de las Ciencias y las Matemáticas IBECERMA. II Taller Regional. Organización de Estados Iberoamericanos para la Educación, la Ciencia y la Cultura. Bogotá Colombia; Sep 17 al 20 de 1991.

Gil, D. (1993). Contribución de la Historia y de la Filosofía de las Ciencias al desarrollo de un Modelo de Enseñanza / Aprendizaje como Investigación. Enseñanza de las Ciencias. 11 (2), 197-212.

Gil, D., y Vilches, A. (2004). La contribución de la ciencia a la cultura ciudadana. Cultura y Educación, 16 (3), 259-272.

Giordán, A. y De Vecchi, G. (1988). Los Orígenes del Saber: De las Concepciones Personales a los Conceptos Científicos. Sevilla. (España): Diada Editores.

González, M., López, J., Luján, J. (2000). Ciencia, Tecnología y Sociedad. Una Introducción al Estudio Social de la Ciencia y la Tecnología. Madrid: Editorial Tecnos S.A.

Jenkins, E. W. (1999). Comprensión pública de la ciencia y enseñanza de la ciencia para la acción. Revista de Estudios del Curriculum. Vol 2 No. 2. 1999. http://www.edpomares. com/libros/rec22int.htm

Llopis G, Ramón (2003). La "Tercera Cultura" como Cultura de Consumo de Masas. "Sección I. Cultura Científica y Cultura Humanista: ¿Se Puede Superar la Escisión? Página 97 de 206. Actas Congreso Internacional. La Ciencia ante el Público: Cultura Humanista y Desarrollo CientíficoTecnológico. 28 al 31 de octubre de 2002. Universidad de Salamanca.

Llorens, J. (1991). Comenzando a Aprender Química. Ideas para el Diseño Curricular. Madrid: VISOR. 
Haynes, R. D. (1994). From Faust to Strangelove. Representations of the Scientist in Western Literature. The Johns Hopkins University Press, Baltimore.

Hodson, D. (1985) Philosophy of science, science and science education. Studies in Science Education, 12, 25-57.

Holbrook, J. (1998). Proyecto 2000+: Cambiando la enseñanza de la ciencia para el siglo XXI. Educar, Curitiba, 14, 69-90. Editora da UFPR. UNESCO.

Holton, Gerald (2001). Ciencia y AntiCiencia. Barcelona: NIVOLA.

Jay Gould, Stephen. (1999). Ciencia versus Religión. Un Falso Conflicto. Barcelona: Crítica.

Martín, Á. (2003). Ambos son Cultura. Congreso Internacional sobre La Ciencia ante el Público: Cultura Humanista y Desarrollo Científico-Tecnológico, Salamanca, 28-31 octubre de 2002. (paper).

Mellado,V., y Carracedo, D., (1993). Contribuciones de la Filosofía de las Ciencias a la Didáctica de las Ciencias. Enseñanza de las Ciencias. 11 (3), 331-339.

Mora P.W. (1997). Naturaleza del Conocimiento Científico e Implicaciones Didácticas. Educación y Pedagogía. № 18. Facultad de Educación. Universidad de Antioquia. pp 133 - 144.

Mora, W., García, A., y Mosquera, C., (2002). Bases para la construcción de un cuerpo conceptual didáctico del desarrollo histórico epistemológico de los conceptos estructurantes de la química. Revista Científica, No. 4, 259-286. Bogotá: Centro de Investigaciones y Desarrollo científico. Universidad Distrital.
Mora, W. y Parga, D. (2005). De las investigaciones en preconcepciones sobre mol y cantidad de sustancia, hacia el diseño curricular en química. Educación y Pedagogía. Universidad de Antioquia. Vol. XVII. No. 43, 164-175.

Mora, W. y Parga, D. (2005b). Evaluación por Competencias y Estándares de Competencia, En el Campo de la Enseñanza de las Ciencias y Educación Ambiental. Revista: Enunciación. No. 10, 73-84.

Mora, W., y Parga, D. (2007). Tramas históricoepistemológicas en la evolución de la teoría estructural en química orgánica. Tecné, Episteme y Didaxis: TED No. 21, 100-118.

Mora, W., y Parga, D. (2008). El Conocimiento Didáctico del Contenido en Química: Integración de las Tramas de Contenido / histórico - epistemológicas con las tramas de Contexto / Aprendizaje. Tecné, Epistemé y Didaxis (TED) No. 24, 54-74. [http://www. pedagogica.edu.co/revistas/ojs/]

Moreno L. M. (2001). El laboratorio del Dr. Frankenstein. Una reflexión acerca de la percepción social de la tecnociencia. La Ciencia es Cultura. /I Congreso sobre Comunicación Social de la Ciencia. Valencia 28, 29 y 30 de noviembre de 2001.

Mosterín, J. (2003). El Espejo Roto del Conocimiento y el Ideal de una Visión Coherente del Mundo. Página 50 de 88 Sesiones Plenarias. Actas Congreso Internacional. La Ciencia ante el Público: Cultura Humanista y Desarrollo CientíficoTecnológico. 28 al 31 de octubre de 2002. Universidad de Salamanca.

Navarro, B.V. (1983). La Historia de las Ciencias y la Enseñanza de las Ciencias. Enseñanza de las Ciencias. 1(1), pp 50-54. 
La imagen pública de la química y su relación con la generación de actitudes hacia la química y su aprendizaje William Manuel Mora Penagos | Diana Lineth Parga Lozano

Nentwig, P. and Demuth, R. (2007). Chemie im Kontext: Situating Learning in Relevant Contexts while Systematically Developing Basic Chemical Concepts. Journal of Chemical Education. Vol. 84 No. 9 September 2007.

Orlik, Y. (2002). Química. Métodos activos de enseñanza aprendizaje. México: Grupo Editorial Iberoamérica S.A.

Porlán, A.R. (1998). Pasado, Presente y Futuro de la Didáctica de las Ciencias. Enseñanza de las Ciencias. 16 (1). pp 175-185

Romo, A. V. M. (1998). La Enseñanza de la Química y su Relación con las Actitudes de los Estudiantes Hacia la Química. Valencia (España). Tesis Doctoral Inédita.

Sagan, C. (2002). El Mundo y sus Demonios. La Ciencia como una Luz en la Oscuridad. Bogotá: Editorial Planeta Colombiana S.A.

Schibecci, R. A. (1984). Attitudes to science: an update. Studies in science education, 11, 26-59.

Shrigley, R. L and Jhonson, J. M. (1974). The Attitude of In Service Elementary Teachers Toward Science. School Science and Mathematics. Vol 74. No 5 . Whole 655. May-Jun.

Schummer, J., Bensaude-Vincent, B., Van Tiggelen, B., (2006). Special Issue on "The Public Image of Chemistry", Part I. Editorial. HYLE -International Journal for Philosophy of Chemistry. Vol. 12, No.1 pp. 3-4. http://www.hyle.org/journal/ issues/12-1/editorial.htm

Sutman, F.; Matthew, B. (1992). Chemistry in the Community-ChemCom. A Five-
Year Evaluation. Journal of Chemical Education. Volume 69 Number 7 July 1992.

Tena, J. (2003). La Ciencia Desapercibida. Página 112 de 123 Sesiones Invitadas. Actas Congreso Internacional. La Ciencia ante el Público: Cultura Humanista y Desarrollo Científico-Tecnológico. 28 al 31 de octubre de 2002. Universidad de Salamanca.

Tudor, A. (1996). Monsters and Mad Scientists. A Cultural History of the Horror Movie. Basil Blackwell, Cambridge, 1989 (citado en Evans, 1996).

Woolgar, S. (1991). Ciencia: Abriendo la Caja Negra. Barcelona: Anthropos.

Yager, R. E. y Penich, J. E. (1986). Perception of Four Age Groups Towards Science Classes, Teachers and the Values in Science. Science Education. Vol.70. pp 355-363.

Yager, R. E. (1992). "Science-TechnologySociety as Reform", en: The Status of Science-Technology-Society Reform. Efforts around the World, International Council of Associations for Science Education, ICASE Yearbook, Petersfield, UK,

Ziman, J. (1991) "Public Understanding of Science," Science, Technology and Human Values 16: 99-105.

Ziman, J. (2003). Science And Civil Society. Páginas 70 de 88 Sesiones Plenarias. Actas Congreso Internacional. La Ciencia ante el Público: Cultura Humanista y Desarrollo Científico-Tecnológico. 28 al 31 de octubre de 2002. Universidad de Salamanca. 